\title{
Bolsonaro, Meio Ambiente, Povos e Terras Indígenas e de Comunidades Tradicionais: uma visada a partir da Amazônia'
}

\author{
HENYO TRINDADE BARRETTO FILHO \\ Universidade de Brasília, Brasília, Distrito Federal, Brasil \\ henyo.barretto@gmail.com
}

DOI 10.11606/issn.2316-9133.v29i2pe178663

Há certa controvérsia sobre o que exatamente significa o advento do governo Bolsonaro na história social, política e econômica recente do país. Longe de querer resolver essa querela, mesmo porque a gravidade do que está em jogo alcança todas as dimensões da vida na sociedade brasileira, talvez olhar para desenvolvimentos recentes na Amazônia brasileira nos ajude a entender o que está se passando - em especial, no que concerne ao que se poderia chamar das antipolíticas "ambiental" e "indigenista" em curso.

Para tanto, contudo, um pouco de história se faz necessário. Mesmo porque, é do repertório de imagens, políticas e tropos historicamente projetados sobre e para a região que o atual governo restaurou elementos importantes para construir a sua plataforma - cujos efeitos nefastos se fazem sentir por toda a parte.

Correndo o risco de generalização, não estaríamos longe da verdade ao afirmar que a Amazônia brasileira parece ter sempre ocupado o lugar de fronteira de recursos nos projetos colonial e nacional - o almoxarifado do país, nos termos de Egídio Schwade. Pivô geográfico, a região foi objeto de iniciativas de valorização tão antigas quanto o próprio país. A própria conformação da "questão Amazônica" é contemporânea da constituição das sociedades nacionais sul-americanas. Antes mesmo destas existirem como unidades territoriais e políticas independentes, a Amazônia já havia sido enlaçada pelos "processos de globalização originários", que "retiraram-lhe a inocência e lançaram-lhe no jogo das forças internacionais

\footnotetext{
${ }^{1}$ Agradeço os pertinentes comentários e recomendações feitos por um parecerista anônimo e endossados pela Comissão Editorial no processo de revisão do texto, que procurei incorporar e contribuíram muito para aprimorá-lo. Eventuais equívocos e inconsistências que tenham permanecido são de minha inteira responsabilidade.
} 
do mercantilismo, do absolutismo monárquico, do absolutismo ilustrado, da acumulação originária, da Razão” (SILVA 1994: p.4).

Esse enlace com o mundo e a ordem global parece ter sempre alarmado as elites nacionais. A rigor, houve uma grande dificuldade da sociedade nacional se configurar na região. Nunca é demais lembrar que havia mais de uma unidade administrativa portuguesa na América do Sul: os estados do Brasil e do Grão-Pará \& Maranhão - este existente desde 1621, renomeado sucessivamente em 1654 e 1751, e desmembrado em 1772 nos estados do GrãoPará \& Rio Negro e do Maranhão \& Piauí. Todas essas unidades administrativas eram colônias autônomas portuguesas subordinadas diretamente à Coroa, em Lisboa. A historiografia contemporânea da Amazônia tem enfatizado, com propriedade, a desconexão entre os Estados do Brasil e o do Grão-Pará mesmo após a instalação da família real no Rio de Janeiro, em 1808, e a fundação do Reino Unido do Brasil. Belém permanecerá vinculada diretamente a Lisboa e, na prática, desligada do que ocorria no Rio de Janeiro até 1823, quando o Estado do Grão-Pará foi autoritariamente anexado pelo Império do Brasil recém fundado. Assim, a "Independência do Brasil” chegou à Amazônia com um ano de atraso e se impôs com muita dificuldade, arrastando-se por vários anos de luta contra as forças que pretendiam manter a região como colônia de Portugal.

Das tensões resultantes desse processo - entre as quais a relativa marginalização da elite do Grão-Pará, que se ressentia do seu isolamento do restante do Império, da sua irrelevância política para a Coroa e de não participar nas decisões do governo central resultou a Cabanagem, a maior revolta popular e social ocorrida no Império, de 1835 a 1840. É possível dizer que a intensa repressão à Cabanagem, um massacre que gerou acentuada depopulação em toda a região, tenha sido o primeiro e violento ato de afirmação da soberania nacional sobre a Amazônia - há não mais de 180 anos, portanto. É dessa época a imagem da Amazônia como um vazio demográfico - imagem esta ancorada no processo efetivo de depopulação promovido pela repressão (FISHER 1995).

Não à toa, entramos no período republicano com as elites assombradas com a possibilidade da Amazônia indômita se despregar do país - tal como no tropo da jangada de pedra que José Saramago usou para se referir a Portugal. Em 1904, após percorrer uma parte da Amazônia como chefe da Comissão Brasileira de Reconhecimento do Alto Purus, Euclides da Cunha mencionou o risco da região se destacar do país "naturalmente e irresistivelmente" (CUNHA 2013: p.44). Getúlio Vargas, ao início da "Marcha para o Oeste", em 1938, sob a ordem do Estado Novo, apregoou que caberia ao país transformar a "força cega da Amazônia em energia disciplinada" (KUEHLS 1996: xiii). Em seu último mandato como Presidente, Vargas instituiu, em 1953, o Plano de Valorização Econômica da Amazônia, com o objetivo de promover o desenvolvimento da produção agropecuária e a integração da região à economia nacional (pois ela estaria muito isolada do resto do país e subdesenvolvida), e criou uma 
Superintendência (SPVEA) para tocar esse plano. É dessa época o conceito de Amazônia Legal, que é reinventado em 1966, com a extinção da SPVEA e criação da SUDAM (Superintendência do Desenvolvimento da Amazônia) para fins de planejamento.

Foram inúmeras, portanto, as iniciativas de "valorização" e "desenvolvimento" da Amazônia ao longo da história, em especial no período republicano, todas de viés autoritário, colonial, tecnocrático e modernizante ${ }^{2}$. A diferença das iniciativas da ditadura civil-militar brasileira em relação às anteriores foram o esforço por imbricar a ciência e a tecnologia com as estruturas do poder e a propensão para uma ação estatal autônoma, típicas do planejamento centralizado e autoritário da ditadura - considerando a concepção dominante que se tinha do lugar do país na ordem internacional àquela época. Tratava-se, segundo o discurso oficial hegemônico de então, de superar os obstáculos à exploração dos recursos - as grandes distâncias (o isolamento), o ambiente inóspito (o inferno verde) e o vazio demográfico (imagens que persistiram) - por meio de ações do Estado, seja induzindo a migração e a colonização (por meio do Programa de Integração Nacional), seja estabelecendo polos de desenvolvimento (por meio da concepção arquipelágica do Polamazônia) e os vários tipos de redes necessários à integração nacional (viária e de telecomunicações).

Ocorre que a projeção dos desenhos feitos na prancheta dos arquitetos dos PNDs ("planos nacionais de desenvolvimento") abriu uma caixa de Pandora, deflagrando dinâmicas socioambientais predatórias e violentas. Parte destas encontra-se retratada não só na literatura acadêmica, mas numa vasta filmografia de época e contemporânea, documental e ficcional, que mostra o que significou a efetiva implementação de tais planos. O antropólogo Shelton Davis expôs, ainda na década de 1970, o que a megalomania desenvolvimentista da ditadura significou para os povos originários em seu livro As Vitimas do Milagre (DAVIS 1977). Na década de 1980, os episódios da série A Década da Destruição, filmados ininterruptamente de janeiro de 1980 a setembro de 1990 pelos realizadores Adrian Cowell e Vicente Rios, numa coprodução da Central Television de Londres com a Universidade Católica de Goiás, mostraram as distintas e dramáticas dimensões desse processo para indígenas, comunidades tradicionais e para os próprios colonos que migraram para a região (COWELL 1990). Só contemporaneamente, contudo, está sendo possível aquilatar a magnitude do genocídio: a Comissão Nacional da Verdade (CNV), trabalhando com um número limitado de dez povos indígenas, estimou para o período investigado (1964 a 1985) pelo menos 8.350 indígenas mortos em massacres, tentativas de extermínio, esbulhos de terras, remoções forçadas, contágio por doenças infectocontagiosas, prisões, torturas e maus tratos (BRASIL 2014). O Relatório Figueiredo, redescoberto em 2012 no bojo dos trabalhos da CNV, traz, em suas mais de sete mil páginas, relatos circunstanciados do procurador Jader de Figueiredo Correia sobre

2 As considerações neste e nos próximos dois parágrafos se baseiam livremente em Almeida (1994), Becker (1990), Davis (1977), Ministério do Meio Ambiente (1997) e Viveiros de Castro (1996). 
violências praticadas por latifundiários brasileiros e funcionários do Serviço de Proteção ao Índio (SPI) contra indígenas ao longo de três décadas (1940 a 1960). ${ }^{3}$

No último quarto do século $\mathrm{XX}$, contudo, remando contra essa maré durante o período que se convencionou chamar de redemocratização da sociedade brasileira, movimentos sociais de base local (o movimento indígena, o dos seringueiros, a Aliança dos Povos da Floresta), ativistas (do florescente processo de organização da sociedade civil), políticos e acadêmicos/cientistas - antropólogos aí incluídos - promoveram profundas transformações nas ideias sobre a histórica ecológica e cultural da Amazônia, e ajudaram a construir para todo o país um modesto, porém consistente, sistema de regulação ambiental. Embora não hegemônica, a visão que se tem hoje da Amazônia em amplos círculos é a de uma região originalmente populosa e sociopoliticamente complexa, um sistema biogeográfico composto por diversos ecossistemas, cada qual com peculiaridades e histórias específicas de constituição, em que a plasticidade da intervenção humana e a engenhosidade de diferentes regimes de conhecimento teriam desempenhado um papel. Tal visão se consolidou nas duas décadas que se seguiram à Conferência das Nações Unidas sobre o Meio Ambiente e Desenvolvimento (Eco-92 ou Rio-92) no contexto da "política internacional em torno do desmatamento da Amazônia" (HURRELL 1992).

Nesse período, ensaiou-se construir caminhos diferentes, com recursos e apoio da cooperação internacional (BARRETTO FILHO 2004) à potencialização das virtualidades socionaturais singulares da Amazônia - seus recursos naturais, econômicos, sociais e culturais endógenos - e à participação institucionalizada de redes de movimentos sociais, num movimento mais bottom-up. Isso se deu a partir de meados dos anos 1980: os anos dos "primeiros encontros" - dos seringueiros, dos povos da floresta, dos impactados por barragens e outros - e de "crise dos padrões tradicionais de relação política na Amazônia" (ALMEIDA 1994). Foi quando mais se reduziu a taxa de desmatamento e mais se avançou no reconhecimento de Terras Indígenas, na criação de áreas protegidas (incluindo as Reservas Extrativistas) e no fomento à formação de economias agroextrativistas de base local.

Esses desenvolvimentos representaram uma séria ameaça à economia de fronteira convencional, que nunca se desarticulou, pois, a inserção do Brasil na ordem econômica internacional como provedor de recursos primários e produtor de commodities de baixo input tecnológico para exportação sempre prevaleceu. Isso explica o favorecimento da economia neoextrativista na Amazônia: pecuária de grande escala em pastagens de baixa produtividade; monocultivos de eucalipto, soja e cana; complexos minerários com minas a céu aberto; minerodutos com quilômetros de extensão; megaprojetos de hidrelétricas (Jirau e Santo Antônio, no rio Madeira; Belo Monte, no rio Xingu; e São Luiz do Tapajós, planejada para o

\footnotetext{
${ }^{3} \mathrm{O}$ recente trabalho de jornalismo investigativo de Valente (2017) veio trazer mais elementos para completar de modo qualificado esse quadro.
} 
rio homônimo) e sistemas portuários. Tudo isso - manutenção da agenda das grandes obras de infraestrutura e estreitamento dos vínculos com o agronegócio, via as várias fases do Programa de Aceleração do Crescimento (PAC) - tendo ocorrido no âmbito dos governos "democráticos e populares" do PT, com efeitos violentíssimas nos territórios e vidas dos povos indígenas e comunidades tradicionais, que nunca baixaram a guarda diante desse modelo e o cerceamento de seus direitos ao longo de todo desse período. A luta do movimento indígena se deu tanto por dentro quanto por fora do Estado: seja ampliando e qualificando sua incidência política nos espaços institucionalizados de participação social, via Comissão Nacional de Política Indigenista e outros conselhos de políticas públicas; seja mobilizando-se e pressionando por meio do Acampamento Terra Livre (ATL), congregado pela primeira vez em $2004^{4}$.

Assim sendo, para entender desenvolvimentos recentes no governo Bolsonaro, poderíamos - conforme sugerido por um parecerista - enfocar os contrastes, semelhanças e rupturas entre três momentos recentes da história do país: os já referidos períodos da ditadura civil militar e do ciclo democrático (em sua oscilação entre liberalismo e social-democracia), e o atual governo. Não obstante, em texto recente (Barretto e Ramos, 2019: 323), preferimos acompanhar o modo como muitas lideranças do movimento indígena ordenam a história contemporânea dos seus direitos também em três momentos, mas relativamente concomitantes com o período pré-Constituição e com tendências observáveis nos sucessivos governos posteriores: uma primeira época carismática, heroica e voluntarista, de resistência à violência e luta para que seus direitos fossem plasmados na Constituição; um segundo momento, mais burocrático, pragmático e profissional, em que o associativismo indígena explodiu e lutou pela implementação de tais direitos no chão - relativamente coincidente com os governos Collor a Lula; e o terceiro e inquietante momento atual, de luta para que não se suprimam tais direitos - que começa a se desenhar ainda no segundo mandato de Lula, com o PAC.

Então, qual a novidade sob Bolsonaro? Trata-se, a meu juízo, de uma combinação peculiar. De um lado, há a reativação de concepções geopolíticas autoritárias baseadas em preceitos de "segurança nacional" e uma visão militarista de soberania, fundada na noção de

\footnotetext{
${ }^{4}$ Em texto recente (BARRETTO FILHO; RAMOS, 2019), ensaiamos uma interpretação sobre a aparente contradição entre as experiências participativas de políticas públicas e a forma autoritária de implantação das obras e iniciativas do PAC nos governos do PT, em que também lembramos da manutenção nestes da estrutura bipartida da política agrária instituída no governo Fernando Henrique. No texto, notamos "a tensão permanente entre as demandas do movimento indígena por cada vez mais democracia participativa e a disciplinarização dessa mesma mobilização indígena" (p.335); e observamos que "o protagonismo contínuo do movimento indígena e das organizações da sociedade civil em luta contra a erosão dos direitos, em especial nos governos Lula e Dilma, produziu um legado de formulações e propostas que pode ser reavivado, caso logremos redefinir a atual correlação de forças” (p.341).
} 
"fronteira viva", ou vivificada pelas já referidas atividades econômicas neoextrativistas convencionais - de que é exemplo o Programa Barão do Rio Branco, anunciado em fevereiro de 2019, mas ele mesmo a retomada de um projeto acalentado durante décadas pelos militares ${ }^{5}$. De outro, observa-se o desbloqueio absoluto - sem sequer um verniz de regulação - dos vetores que configuram a economia de fronteira, que sempre operaram na região, por meio tanto de posicionamentos públicos, quanto de medidas governamentais, tais como: a reiteração do argumento xenófobo de que a interferência estrangeira em terras indígenas e na proteção ambiental dificulta o progresso do país, a que respondem as diretrizes de não demarcar mais Terras Indígenas, rever a criação de áreas protegidas e abrir tais territórios ao desenvolvimento comercial $^{6}$; a desarticulação do sistema de regulação ambiental, em especial a revisão em curso da legislação sobre licenciamento ambiental de empreendimentos, o relaxamento geral da fiscalização e o "assédio moral coletivo" a que estão submetidos os profissionais desta área ${ }^{7}$; o uso sistemático de informações mentirosas e distorcidas sobre inúmeras questões ambientais ${ }^{8}$; a afirmação de que os dados sobre o desmatamento gerados pelo Instituto Nacional de Pesquisas Especiais são manipulados - que é parte da ofensiva mais ampla contra a educação, a pesquisa científica e as instituições responsáveis por estas.

Tudo isso tem transmitido, desde antes mesmo do início do governo, a sensação generalizada de que o governo "liberou geral". Como disseram posseiros armados que invadiram Terras Indígenas em Rondônia: “Agora Bolsonaro é presidente!”. Isso se faz sentir em repercussões gravíssimas na Amazônia como um todo, tais como: a invasão sistemática a áreas protegidas e Terras Indígenas (Uru-Eu-Wau-Wau, Karipuna, Xipaia, Arara, Awa Guajá)

5 Planejado para ser implantado no norte do estado do Pará, na região referida como Calha Norte, o Programa prevê a construção de uma usina hidrelétrica no rio Trombetas, a edificação de uma grande ponte sobre o rio Amazonas nas imediações da cidade de Óbidos, o prolongamento da BR-163 até a fronteira com o Suriname e a implantação de um "polo de desenvolvimento" regional - tudo isso entrecortando e se sobrepondo a terras indígenas, territórios quilombolas e unidades de conservação. O Programa foi severamente criticado por organizações nacionais, regionais e locais do movimento indígena, e pela Associação Brasileira de Antropologia, suas comissões e comitês, todas preocupadas com o fragrante descumprimento de dispositivos legais relativos aos direitos humanos e ambientais, especialmente dos povos indígenas, quilombolas e comunidades tradicionais a serem afetados (ver a nota técnica assinada pela APIB, COIAB, APOIANP e FEPIPA sobre o projeto Barão de Rio Branco, e a nota da Associação Brasileira de Antropologia, também sobre o projeto).

6 Ver reportagem de Jussara Soares publicada no jornal O Globo de 04/07/2019.

7 Ver reportagem da revista Exame de 26/06/2019 sobre denúncias de servidores do IBAMA contra o ministro do meio ambiente, Ricardo Salles.

8 Ver a carta da Coalizão Ciência e Sociedade de 05 de julho de 2019, intitulada "O Governo e o Desmatamento: a negação como mecanismo de defesa”. Ver também matéria do Observatório do Clima, de 09/07/2019, sobre o assunto. 
logo no primeiro mês de governo; ; a retomada da invasão da Terra Indígena Yanomami por dezenas de milhares de garimpeiros, em patamares similares à grande invasão de $1992^{10}$; a explosão da taxa de desmatamento, que já em junho de 2019 registrava um aumento de $60 \%$ em relação ao mesmo mês do ano anterior ${ }^{11}$ e que não para de crescer desde então; e a intensificação da grilagem de terras, da mineração clandestina em larga escala e da exploração madeireira predatória, com a criminalidade que costuma acompanha-las - entre outros desdobramentos igualmente nefastos para os povos e comunidades que vivem em estreita interação com os ecossistemas da região. É como se estivéssemos revendo os episódios da série de Adrian Cowell e Vicente Rios.

Assim, o que se passa na Amazônia hoje - como um espelho que reflete dinâmicas em curso em todo o país - parece confirmar a sugestão de Pinto Neto (2019), segundo o qual não estaríamos diante de um autoritarismo clássico, baseado em leis e instituições sob o comando de um ditador, mas de um governo que desbloqueia os freios à violência opressiva e deixa correr um laissez-faire na sociedade civil (no seu sentido amplo), liberta de quaisquer limites legais. Pense-se, por exemplo, nas medidas de flexibilização de compra e posse de armas de fogo por moradores de áreas rurais e cidades violentas, e proprietários de estabelecimentos comerciais $^{12}$. Ao desbloquear esses freios, possibilitando silenciar - com violência simbólica e/ou física - os opositores e eliminar as mediações propiciadas pelo sistema de regulação ambiental, tratar-se-ia agora de liberar as forças cegas - para usar os termos de Getúlio Vargas a contrapelo - do voluntarismo e do senso comum para completar a rapinagem do butim que os dispositivos coloniais autoritários anteriores não lograram usurpar totalmente.

Frente a essa situação, povos e comunidades tradicionais continuam a se organizar em redes de movimentos, adotando, muitas vezes, medidas de confrontação aberta (bloqueios e ocupações) e proclamando a disposição de reagir ainda mais energicamente. A intensificação dessas redes de alianças envolve instituições de ensino e pesquisa, de defesa dos direitos humanos e organizações não governamentais, objetivando a denúncia de violações de direitos nos âmbitos nacional e internacional. Outra linha de oposição tem sido a sistematização de saberes locais na forma de publicações (como material didático e de divulgação) que enfatizam a centralidade dos modos de vidas e dos regimes conhecimento dos povos indígenas e comunidades tradicionais para a manutenção de múltiplas formas de vida, e promovem o

\footnotetext{
9 Ver notícias do portal A Crítica, sobre invasão de terras indígenas, publicada em 06/03/2019, de Rubens Valente para a Folha de São Paulo em 04/01/2019 sobre o contexto paraense, do portal Notícias Ao Minuto de $\underline{31 / 03 / 2019}$ e do portal G1 sobre invasão de terras indígenas no Maranhão, publicada em 16/01/2019

10 Ver nota publicada no Portal do Instituto Socioambiental em 29/05/2019.

11 Ver reportagem do Jornal O Globo de 01/07/2019.

12 Ver reportagem do jornal Correio do Povo sobre liberação de uso de armas em áreas rurais, publicada em $10 / 01 / 2019$.
} 
reconhecimento dos direitos desses grupos. Persistem, contudo, os riscos de retrocesso no reconhecimento dos direitos constitucionais desses coletivos (por meio de medidas legislativas de vários níveis), de criminalização de tais movimentos e até dos técnicos e instituições que atuam junto a esses coletivos. A questão que fica para nós é se as estratégias e linhas de oposição darão conta de barrar o avanço da barbárie.

\section{Referências Bibliográficas}

ALMEIDA, Alfredo Wagner de. (1994) [1989]. "Universalização e localismo: movimentos sociais e crise dos padrões tradicionais de relação política na Amazônia”. In: D’INCAO, Maria Ângela; SILVEIRA, Isolda Maciel (orgs.). Amazônia e a Crise da Modernização. Belém: Museu Paraense Emilio Goeldi. pp. 521-537.

BARRETTO FILHO, Henyo. Trindade. (2004). "Meio Ambiente, 'realpolitik', reforma do Estado e ajuste fiscal”. In: ROCHA, Denise; BERNARDO, Maristela; et al. (orgs.) A Era FHC e o Governo Lula: transição? Brasília: Inesc. pp. 327-358.

BARRETTO FILHO, Henyo Trindade. (2018). Reparação e Descolonização como Eixos da Política Indigenista: um trecho original do documento-base da $1^{\text {a }}$ Conferência Nacional de Política Indigenista. Vukápanavo: Revista Terena, vol.1, n.1, pp.80-106.

BARRETTO FILHO, Henyo Trindade; RAMOS, Alcida. (2019). "Da luta por direitos à luta para não perdê-los: povos e terras indígenas (TIs) na guerra pela destinação de terras públicas no Brasil pós-Constituição”. In: ARRETCHE, Marta; MARQUES, Eduardo; FARIA, Carlos Aurélio Pimenta de. (orgs.). As Políticas da Politica: desigualdades e inclusão nos governos do PSDB e do PT. São Paulo: Editora Unesp. pp. 321-344.

BECKER, Berta. (1990). "Gestão do território e territorialidade na Amazônia: A CVRD e os garimpeiros na província mineral de Carajás”. In: BECKER, Berta K; MIRANDA, Mariana Miranda; MACHADO, Lia Osório. (Orgs). Fronteira Amazônica: questões sobre a gestão do território. Brasília: Editora UnB. pp. 197-214.

BRASIL. Comissão Nacional da Verdade (CNV). 2014. "Texto 5 - Violações de direitos humanos dos povos indígenas”. Relatório. Volume II: Textos temáticos. Brasília: CNV. pp. 20362.

COWELL, Adrian. (1990). The Decade of Destruction. Sevenoaks, UK: Hodder \& Stoughton.

CUNHA, Euclides da. (2013) [1904]. "Entre o Madeira e o Javari”. Seleta: textos sobre o Brasil. Rio de Janeiro: Fundação Darcy Ribeiro (Col. Biblioteca Básica Brasileira, 18). pp. 39-44.

DAVIS, Shelton. (1977). The Victims of the Miracle: Development and the Indians of Brazil. Cambridge: Cambridge University Press.

FISHER, William Halder. (1995). "Native Amazonians and the Making of the Amazon Wilderness: from Discourse of Riches and Sloth to Underdevelopment”. In DUPUIS, 
Melanie E.; VANDERGEEST, Peter. (orgs.). Creating the Countryside: The politics of rural and environmental discourse. Philadelphia: Temple University Press. pp.166-203.

HURRELL, Andrew. (1992). "Brazil and the international politics of Amazonian deforestation”. In: Hurrell, Andrew; KINSGBURY, Benedict. (eds.), The International Politics of the Environment: Actors, interests and institutions. Oxford: Clarendon Press. pp. 398-429.

KUEHLS, Thom. (1996). Beyond Sovereign Territory. Minneapolis: University of Minnestota Press.

MMA (Ministério do Meio Ambiente). (1997). Agenda Amazônia 21: bases para discussão. Brasília: MMA, Secretaria de Coordenação da Amazônia.

PINTO NETO, Moyses. (2019). O Projeto bolsonarista não é um autoritarismo clássico baseado em leis e instituições sob comando do ditador. É um governo do caos que desbloqueia os freios à violência opressiva e deixa espécie de laissez-faire na sociedade civil liberta dos limites legais. 09 de jul de 2019. Twitter: @moysespintonet0. Disponível em https://twitter.com/moysespintonet0/status/1148580692240080902. Acesso em 13 de jul de 2019.

SILVA, Marilene Corrêa da. (1994). Os Processos de Globalização na Amazônia. Trabalho apresentado no GT "Sociologia da Cultura Brasileira”, no XVIII Encontro Anual da ANPOCS, Caxambu-MG.

VALENTE, Rubens. (2017). Os Fuzis e as Flechas: história de sangue e resistência indígena na ditadura. São Paulo: Companhia das Letras.

VIVEIROS DE CASTRO, Eduardo. (1996). Images of Nature and Society in Amazonian Ethnology. Annual Review of Anthropology, vol.25: p.179-200.

sobre o autor

\section{Henyo Trindade Barretto Filho}

É antropólogo, professor do Departamento de Antropologia da Universidade de Brasília. Possui doutorado em Antropologia Social pela Universidade de São Paulo e mestrado pelo Museu Nacional da Universidade Federal do Rio de Janeiro.

Recebido em 21/09/2020 Aceito para publicação em 22/12/2020 